\title{
Environmental Regulation, Technology Innovation, and Profit: A Perspective of Production Cost Function*
}

\author{
Ming-Chung Chang \\ Department of Banking and Finance, Kainan University, Chinese Taipei \\ Email: changmc@mail.knu.edu.tw
}

Received October 17, 2013; revised November 17, 2013; accepted November 24, 2013

Copyright (C) 2013 Ming-Chung Chang. This is an open access article distributed under the Creative Commons Attribution License, which permits unrestricted use, distribution, and reproduction in any medium, provided the original work is properly cited. In accordance of the Creative Commons Attribution License all Copyrights @ 2013 are reserved for SCIRP and the owner of the intellectual property Ming-Chung Chang. All Copyright (C 2013 are guarded by law and by SCIRP as a guardian.

\begin{abstract}
The Porter hypothesis asserts that a stricter environmental regulation stimulates firms to conduct innovation and increase their profit. This paper uses a theoretical framework to examine the Porter hypothesis. We conclude that although a stricter environmental regulation can increase profit, it does not stimulate innovation in a firm.
\end{abstract}

Keywords: Porter Hypothesis; Environmental Regulation; Innovation

\section{Introduction}

There was a controversy on whether stringent environmental regulations enhance pollution-reducing innovation and increase firms' benefits or not. In the opinion of Porter and van der Linde [1], the enforcement of environmental regulations not only reduces environmental damage, but also stimulates pollution-reducing innovation and increases firms' profit. This comes to be the renowned Porter hypothesis. Many case studies after Porter and van der Linde [1] support the Porter hypothesis, but they have been criticized by economists for lack of rigorous theoretical foundations. Hence, this paper uses a theoretical framework to examine the Porter hypothesis.

In the case of a game without environmental regulation, we consider a model with a single monopoly firm producing a dirty product. For maximizing monopoly profit, a monopoly firm determines the product's environmental performance at stage 1 and sets the price at stage 2 . In the case of a game with environmental regulation, we consider two agents in the economy: a single monopoly firm deciding a product's environmental performance and a price to maximize profit and a regulator deciding an environmental regulation (an emission standard) to control the emission quantity.

The paper closest to our own is Ambec and Barla [2], who concluded that the Porter hypothesis can hold when

\footnotetext{
*The author appreciates the part of financial support from National Science Committee (NSC 102-2410-H-424-020-).
}

the product's marginal environmental damage is small. In contrast, we find that a strict environmental regulation benefits a firm's profit, but this cannot stimulate it to conduct innovation. This result comes from a difference on the set-up of the cost function. The cost function in Ambec and Barla [2] is separated into the production cost and R\&D cost, and both are addible. However, the cost function in this paper integrates the production cost and R\&D cost. Other papers that seek to justify the Porter hypothesis include Greaker [3], Hart [4], Mohr [5], and more.

The remainder of this paper is organized as follow. Section 2 is the model set-up. Section 3 presents the case of a game without environmental regulation. Section 4 presents the case of a game with environmental regulation. Section 5 offers a comparison of the equilibrium results of the two different games. Section 6 concludes this paper.

\section{The Model}

We consider two agents in an economy. One is a firm $(F)$, and the other is an environmental regulator $(R)$. The firm produces an amount $q$ of a good that generates a level $e$ of pollution. We connect quantity and environmental quality here through a pollutant emissions function as $e=$ $f(q) / \theta$. The emission function is increasing and convex in $q$, where $f(0)=0, f^{\prime}(q)>0$, and $f^{\prime \prime}(q) \geq 0$ shows a positive relationship between the output and the pollution. Parameter $\theta$ is an index for the product's environmental 
performance. A product with a large $\theta$ means that it generates less environmental harm, i.e., a "green” product, where $\theta \in(0, \infty)$. A firm's cost function is described as $c(q, \theta)$, with $c(0, \theta)=0, c_{\theta}(q, \theta)>0, c_{\theta d}(q, \theta)>0, c_{q}(q, \theta)$ $>0$, and $c_{q q}(q, \theta) \geq 0$, where the subscripts stand for partial derivatives, pollution abatement costs are increasingly costly, and marginal production costs are non-decreasing. A firm's cost function in our model also satisfies the traditional hypothesis in the environmental economics literature by Palmer et al. [6], i.e., $c_{q}(q, \theta)>0$.

Polluting emissions damage the global environment and personal health due to the ingestion of polluted air, water, and food. We denote the social cost $D(e)$ as the global environmental damage, and denote the private cost $d(e)$ as the personal health damage. The consumers are a continuous distribution over $[0,1]$. A consumer of type $s$ has a maximized willingness to pay for the product to be $s$, and each consumer purchases at most one unit of the product at price $p$. Since the global environmental damage is the same for each buyer and each non-buyer, it does not affect our analytic result. A buyer's net utility is $s-d(e)-D(e)-p$, while a non-buyer's net utility is $-D(e)$. We assume that $d(0)=0, d^{\prime}(e)>0$, and $d^{\prime \prime}(e) \geq 0$.

\section{Game without Environmental Regulation}

The game without environmental regulation is a twostage game. At stage 1, the firm determines the product's environmental performance. At stage 2, the firm sets the price. We use backward induction to obtain a sub-game perfect Nash equilibrium (SPNE).

$s^{U}$ is assigned as the marginal consumer who is indifferent to buy products or not. The superscript " $U$ " stands for the case of a game without environmental regulation. $s$ is solved through the Equation (1) as follow:

$$
s-d(f(1-s) / \theta)-p=0 .
$$

From Equation (1), we have $s^{U}=s^{U}(p, \theta)$, where $s^{U} \in$ $[0,1]$, and from Equation (1), we obtain the relationship between $s^{U}$ and $p$ by the Implicit Function Theorem as:

$$
s_{p}^{U}=\left(1+d^{\prime} f^{\prime} / \theta\right)^{-1}>0 .
$$

The result of Equation (2) tells us when price $(p)$ increases, it induces the critical point $s^{U}$ to shift to right and it approaches 1 . In other words, when price increases, it makes the demand quantity $\left(1-s^{U}\right)$ decrease. Hence, consumer behavior satisfies the demand law.

The demand function that firm faces is $q^{U}=1-s^{U}$, and the firm's profit function is:

$$
\pi(p, \theta)=p q^{U}(p, \theta)-c\left(q^{U}(p, \theta), \theta\right) .
$$

Deriving Equation (3) with respect to parameter $p$ and let it be zero, we have the result in Stage 2 as:

$$
p=q^{U} / s^{U}+c_{q U} \geq 0 \text {. }
$$

From Equation (1), we also obtain the relationship between $s^{U}$ and $\theta$ by the Implicit Function Theorem as:

$$
s_{\theta}^{U}=\Omega_{1} / \Omega_{0},
$$

where $\Omega_{0}=1+d^{\prime} f^{\prime} / \theta+1 / \theta+d^{\prime} f^{\prime} / \theta^{2}+q d^{\prime \prime} f^{\prime \prime} / \theta^{2}>0$, and $\Omega_{1}=q / \theta^{2}+c_{q \theta}-d^{\prime} f^{\prime} / \theta^{2}$. The sign of $s_{\theta}^{U}$ is decided by the sign of $\Omega_{1}$. When the product's marginal environmental damage is large enough, i.e.,

$d^{\prime}>\left(q+\theta^{2} c_{q \theta}\right) / f$, it induces $\Omega_{1}<0$ and $s_{\theta}^{U}<0$. This implies that given one unit of emission with large health damage to consumers, an increase in a product's environmental performance induces the product's demand quantity to increase.

We next examine the relationship between price $(p)$ and the product's environmental performance $(\theta)$. The comparative static result in Equation (4) is:

$$
\begin{aligned}
& \frac{\partial p}{\partial \theta}=-\left(\frac{\theta+d^{\prime} f^{\prime}+q d^{\prime \prime} f^{\prime \prime}}{\theta^{2}}\right) s_{\theta}^{U}+\frac{q}{\theta^{2}}+c_{q \theta}>0, \\
& \text { for } d^{\prime}>\left(q+\theta^{2} c_{q \theta}\right) / f .
\end{aligned}
$$

This tells us that the clearer the product is, the higher the price will be when the product's marginal environmental damage is large enough. There are two negative effects in a consumer's utility: a large marginal environmental damage of the product and the high price. However, the product's marginal environmental damage can be mitigated by increasing its environmental performance. Hence, when the product's marginal environmental damage is large, the consumers are willing to spend a lot more to purchase the product with high environmental performance. Some studies on marketing research provide various evidence to support our finding such as Cairncross [7], and Cason and Gangadharan [8]. They concluded that some consumers are willing to pay a higher price on biodegradable and 3R (Reduce, Reuse and Recycle) products. We propose this as:

Proposition 1. In a game without environmental regulation, when the product's marginal environmental damage is large, the consumers are willing to pay a high price to purchase the product with a high environmental performance.

We solve the equilibrium solution at stage 1 . Recall the firm's profit function in Equation (3). Derive Equation (3) with respect to parameter $\theta$ and let it be zero. We obtain the optimal product's environmental performance $\theta^{U}$ that maximizes the firm's profit. Substitute $\theta^{U}$ into Equation (4) and Equation (3), and the equilibrium solutions in the game without environmental regulation are $\left\{\theta^{U}, p^{U}, \pi^{U}, e^{U}\right\}$.

\section{Game with Environmental Regulation}

We now introduce an environmental regulation into the game. At stage 0 , the regulator sets the emission standard 
$e^{R}$. The superscript " $R$ " stands for the case with environmental regulation. Since the regulator must consider the influence of environmental emission damage on social welfare, the regulator manages a firm's activity by fixing an upper bound on emission quantity, i.e., $e^{R}<e^{U}$. The regulator's two behavior assumptions are:

Assumption 1 The regulator does not consider the number of purchases when it regulates the emission standard, i.e., $\partial e^{R} / \partial s=0$.

Assumption 2 The emission standard becomes not strict when a firm promotes the product's environmental performance, and both of them have a linear relationship, i.e., $\partial e^{R} / \partial \theta>0$ and $\partial^{2} e^{R} / \partial \theta^{2}=0$. This assumption satisfies the claim by Porter and van der Linde [1] that environmental regulation leads to a firm's innovation.

We now go to the game analysis. The game structure in this section is the same as the game without environmental regulation. A marginal consumer defined as $s^{R}$ is indifferent to buy products or not. Solve $s^{R}$ by the equation:

$$
s-d\left(e^{R}(s, \theta)\right)-p=0 .
$$

From Equation (7), we have $s^{R}=s^{R}(p, \theta)$, where $s^{R} \in$ $[0,1]$, and from Equation (7), we obtain the relationship between $s^{R}$ and $p$ by the Implicit Function Theorem as:

$$
s_{p}^{R}=1>0 .
$$

Since an increase in price makes the critical point of marginal consumer move to the right, i.e., the demand quantity deceases, Equation (8) shows that the consumer's behavior satisfies the demand law. The demand function that the firm faces is $q^{R}=1-s^{R}$, and the firm's profit function is:

$$
\pi(p, \theta)=p q^{R}(p, \theta)-c\left(q^{R}(p, \theta), \theta\right) .
$$

Deriving Equation (9) with respect to parameter $p$ and letting it be zero, we have the equilibrium result in Stage 2 as:

$$
p=q^{R}+c_{q R} \geq 0 .
$$

From Equation (7), we obtain the relationship between $s^{R}$ and $\theta$ as:

$$
s_{\theta}^{R}=d^{\prime}\left(\partial e^{R} / \partial \theta\right)+\partial p / \partial \theta
$$

The sign of $s_{\theta}^{R}$ cannot be confirmed here until the next context since we need to confirm a relationship between $p$ and $\theta$. Deriving Equation (10) with respect to $\theta$, we have:

$$
\frac{\partial p}{\partial \theta}=\left(-d^{\prime}\left(\partial e^{R} / \partial \theta\right)+c_{q R \theta}\right) / 2>0 .
$$

We find that there is a direct relationship between $p$ and $\theta$, implying the consumer is willing to pay a high price to purchase green products. This is because the consumer can increase utility by paying a high price to get a green product. Hence, we have a proposition as follow:

Proposition 2. Under an environmental regulation, the consumer is willing to pay a high price to get green products.

We now recall Equation (11) to examine the sign of $s_{\theta}^{R}\left(=d^{\prime}\left(\partial e^{R} / \partial \theta\right)+\partial p / \partial \theta\right)$. Since $\partial e^{R} / \partial \theta>0$ and $\partial p / \partial \theta$ $>0$, the sign of $s_{\theta}^{R}$ is positive. It shows that when the product's environmental performance increases, the number of consumers who purchase the product will decrease. This result comes from a high product price.

At stage 1, the firm decides the product's environmental performance. Substituting Equation (10) into Equation (9) and deriving it with respect to $\theta$, we have:

$$
\pi_{\theta}=-d^{\prime}\left(\partial e^{R} / \partial \theta\right)\left(1-s^{R}\right)-c_{\theta}<0 .
$$

Equation (13) shows that the product with a low environmental performance will create a high profit for the firm. Hence, $\theta^{R}=0$ maximizes the firm's profit. Substituting $\theta^{R}=0$ into Equation (10) and Equation (9), the equilibrium solutions in the game with environmental regulation are $\left\{\theta^{R}=0, p^{R}, \pi^{R}\right\}$.

\section{Comparison Two Outcomes and Examination of Porter Hypothesis}

We now compare the outcomes of the two different games and examine the implication of the Porter hypothesis by assuming $e=q / \theta, c=q\left(\theta^{2} / 2\right), d=e^{2} / 2$. The cost function here captures the characteristic that there is no cost when the firm produces the lowest environmental performance of a product, i.e., $\theta=0$. By simple calculation, we get the equilibrium solutions in the game without environmental regulation as follow:

$$
\begin{gathered}
\theta^{U}=1 / 2, \\
p^{U}=5 / 8, \\
\pi^{U}=1 / 8, \\
e^{U}=1 / 2 .
\end{gathered}
$$

We next solve the equilibrium solutions in the game with environmental regulation. Since the regulator sets the emission standard $e^{R}$, the environmental damage function is $d=(1 / 2) e^{R 2}$. Letting $s-d\left(e^{R}\right)-p=0$, the marginal consumer is $s^{R}=(1 / 2) e^{R 2}+p$, and the demand quantity is $q=1-s^{R}$. Substituting $q$ into the cost function $c=q(\theta / 2)^{2}$, we have $\pi=p q-c$. By backward induction, we get the equilibrium solutions:

$$
\begin{gathered}
\theta^{R}=0, \\
p^{R} \in[0,0.5],
\end{gathered}
$$




$$
\begin{aligned}
& \pi^{U} \in[0,0.25], \\
& e^{R} \in[0, \sqrt{2}] .
\end{aligned}
$$

A comparison in two different games shows in Table $\mathbf{1}$.

We next use the figure below to illustrate the firm's equilibrium profits in two different games. In Figure 1 we find that when the regulator sets an emission standard $\left(e^{R}\right)$ lower than the emission quantity under the game without environmental regulation $\left(e^{U}=0.5\right)$, the firm's profit $\left(\pi^{R}\right)$ is higher than that under the game without environmental regulation $\left(\pi^{U}\right)$. However, it does not benefit the firm to promote a product's environmental performance since the product's environmental performance under the game with environmental regulation $\left(\theta^{R}=\right.$ 0 ) is lower than that of the game without environmental regulation $\left(\theta^{U}=0.5\right)$. This result is different from Ambec and Barla (2002). They concluded that when the marginal environmental damage of a product is small, an environmental regulation can enhance pollution-reducing innovation and increases the firm's profit. The difference between their conclusion and ours comes from the inde-

Table 1. A comparison in equilibrium result.

\begin{tabular}{ccc}
\hline & $\begin{array}{c}\text { No } \\
\text { Environmental } \\
\text { Regulation }\end{array}$ & $\begin{array}{c}\text { Implementation } \\
\text { Environmental } \\
\text { Regulation }\end{array}$ \\
\hline $\begin{array}{c}\text { Product's Environmental } \\
\text { Performance }(\theta)\end{array}$ & $1 / 2$ & 0 \\
Product's Price $(p)$ & $5 / 8$ & {$[0,0.5]$} \\
Firm's Profit $(\pi)$ & $1 / 8$ & {$[0,0.25]$} \\
Pollutant Emissions $(e)$ & $1 / 2$ & {$[0, \sqrt{2}]$} \\
\hline
\end{tabular}

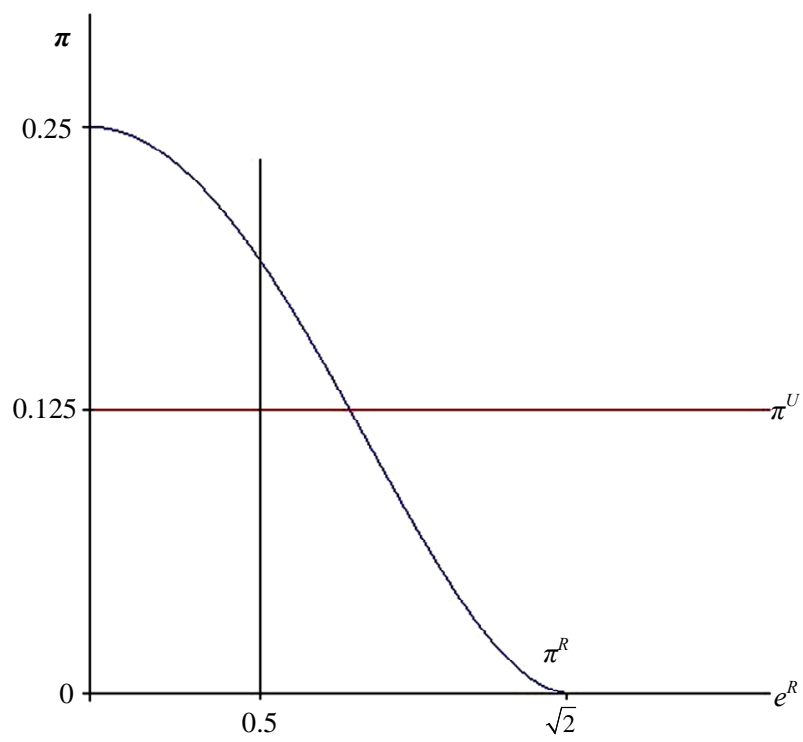

Figure 1. Comparison of profits in two different games. pendence between their production cost and innovation cost. These two costs are relative in ours. Hence, we have the proposition as follow.

Proposition 3. When the production cost and innovation cost are relative, a stringent environmental regulation can increase the firm's profit, but it cannot enhance pollution-reducing innovation.

\section{Concluding Remarks}

Many papers seek to justify the Porter hypothesis, which claims that a stringent environmental regulation will increase a firm's profit and enhance innovation. We use a theoretical framework to examine the Porter hypothesis. The closest article to ours is Ambec and Barla [2], who concluded that when the product's marginal environmental damage is small, the Porter hypothesis holds. The production cost and R\&D cost in their paper are additive. However, these two costs in our paper are relative. Hence, our conclusion is different from Ambec and Barla [2]. We conclude that although a stringent environmental regulation can increase the firm's profit, it cannot enhance its innovation.

\section{REFERENCES}

[1] M. E. Poter and C. van der Linde, "Toward a New Conception of the Environment Competitiveness Relationship,” Journal of Economic Perspectives, Vol. 9, No. 4, 1995, pp. 97-118. http://dx.doi.org/10.1257/jep.9.4.97

[2] S. Ambec and P. Barla, "A Theoretical Foundation of the Porter Hypothesis,” Economics Letters, Vol. 75, 2002, pp. 355-360.

http://dx.doi.org/10.1016/S0165-1765(02)00005-8

[3] M. Greaker, "Spillovers in the Development of New Pollution Abatement Technology: A New Look at the Porter Hypothesis," Journal of Environmental Economics and Management, Vol. 52, No. 1, 2006, pp. 411-420. http://dx.doi.org/10.1016/j.jeem.2006.01.001

[4] R. Hart, "Growth, Environment and Innovation-A Model with Production Vintages and Environmentally Oriented Research,” Journal of Environmental Economics and Management, Vol. 48, No. 3, 2004, pp. 1078-1098. http://dx.doi.org/10.1016/j.jeem.2004.02.001

[5] R. D. Mohr, "Technical Change, External Economies, and the Porter Hypothesis," Journal of Environmental Economics and Management, Vol. 43, No. 1, 2002, pp. 158168. http://dx.doi.org/10.1006/jeem.2000.1166

[6] K. Palmer, W. E. Oates and P. R. Portney, "Tightening Environmental Standards: The Benefit Cost or the NoCost Paradigm?” Journal of Economic Perspectives, Vol. 9, 1995, pp. 119-132. http://dx.doi.org/10.1257/jep.9.4.119

[7] F. Cairncross, "Costing the Earth," Harvard University Press, Cambridge, 1992.

[8] T. N. Cason and L. Gangadharan, "Environmental Label- 
ling and Incomplete Consumer Information in Laboratory

Experiments," Journal of Environmental Economics and
Management, Vol. 43, 2002, pp. 113-134.

http://dx.doi.org/10.1006/jeem.2000.1170 